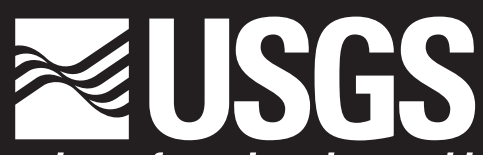

\title{
Global Geologic Map of Ganymede
}

By Geoffrey C. Collins, G. Wesley Patterson, James W. Head, Robert T. Pappalardo, Louise M. Prockter, Baerbel K. Lucchitta, and Jonathan P. Kay

\section{Scientific Investigations Map 3237}

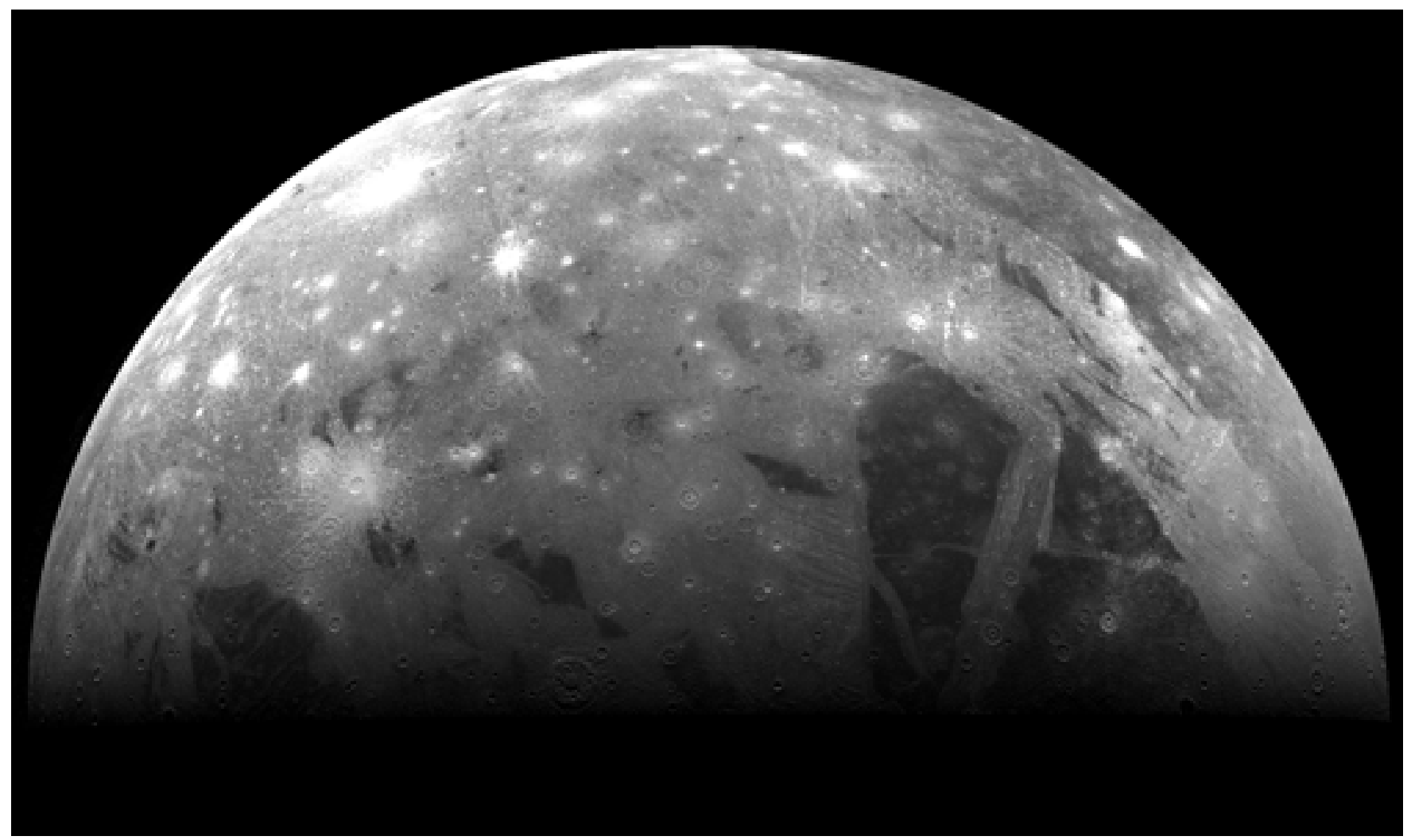

View looking west across the leading hemisphere of Ganymede, captured by the Galileo spacecraft during orbit C9. The north pole is on the right, and the south pole is on the left. On the right, the dark material of Galileo Regio is seen curving off toward the limb, separated from the dark material of Perrine Regio on the terminator by a swath of light material called Xibalba Sulcus. On the left, the westernmost tip of the dark material in Nicholson Regio is seen at the terminator, and the edge of the large impact basin Gilgamesh is just over the limb. (Images from NASA/JPL.) 


\section{Contents}

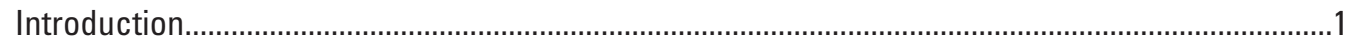

Image data

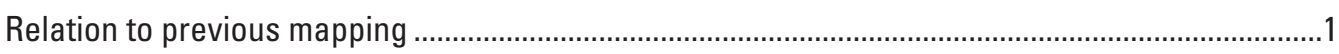

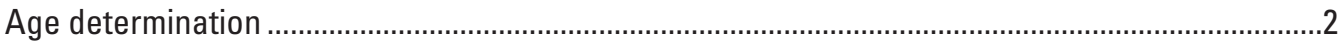

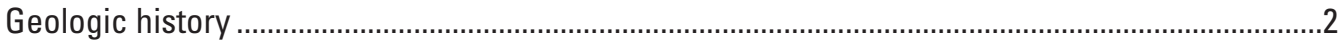

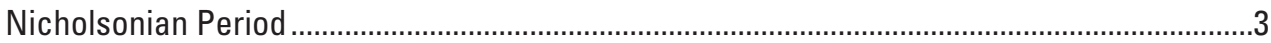

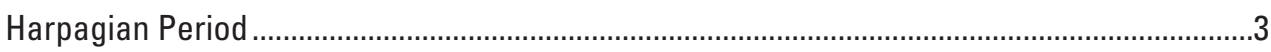

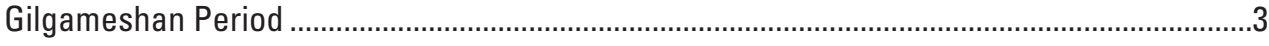

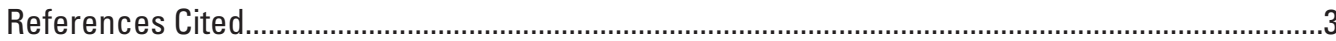




\section{Introduction}

Ganymede is the largest satellite of Jupiter, and its icy surface has been formed through a variety of impact cratering, tectonic, and possibly cryovolcanic processes. The history of Ganymede can be divided into three distinct phases: an early phase dominated by impact cratering and mixing of non-ice materials in the icy crust, a phase in the middle of its history marked by great tectonic upheaval, and a late quiescent phase characterized by a gradual drop in heat flow and further impact cratering. Images of Ganymede suitable for geologic mapping were collected during the flybys of Voyager 1 and Voyager 2 (1979), as well as during the Galileo Mission in orbit around Jupiter (1995-2003). This map represents a synthesis of our understanding of Ganymede geology after the conclusion of the Galileo Mission.

The two fundamental classes of material units on Ganymede are dark materials and light materials. The dark/ light distinction is based on sharp relative albedo contrasts at terrain boundaries, rather than on absolute albedo, because several other types of surface modification (for example, crater rays, polar caps) change the absolute albedo within these terrain classes. Dark materials cover 35 percent of Ganymede's surface; almost the entire remainder of the surface is covered by light materials.

Dark materials are heavily cratered, though not as heavily cratered as the surface of the neighboring satellite Callisto, suggesting that dark materials cannot be a primordial surface (Shoemaker and others, 1982). At high resolution, dark materials are dominated by the downslope movement of loose dark regolith within impact craters and on the sides of bright ridges and hummocks (Prockter and others, 1998). These observations suggest that dark materials are covered by a thin lag deposit of dark regolith derived by sublimation of a more ice-rich crust below (Moore and others, 1999). Dark materials commonly exhibit sets of concentric arcuate structures known as furrows. Furrows may be the remnants of ancient multi-ring impact basins, similar to intact impact basins on Callisto, such as Valhalla and Asgard.

Light materials crosscut dark materials and exhibit a lower impact crater density, demonstrating that they were formed later. Light materials are subdivided into an intricate patchwork of crosscutting lineaments called grooves, mixed with areas of relatively smooth terrain. At high resolution, most light materials are dominated by extensional faulting (for example, Pappalardo and others, 1998; Pappalardo and Collins, 2005). Even light materials that appear to be smooth at low resolution are marked at high resolution by sets of parallel lineaments of apparent tectonic origin. There is an open question on the extent to which light terrain is formed by cryovolcanic flooding of dark material with brighter ice versus tectonic destruction of preexisting surface features and exposure of brighter subsurface ice in fault scarps; it is certainly possible that both of these processes play important roles in the formation of light materials (Pappalardo and others, 2004). Not all tectonic activity on Ganymede has led to the formation of light material — some dark material is cut by extensional faults without exhibiting a major change in albedo, while reticulate material is cut by two sets of tectonic lineaments and is transitional in albedo between adjacent light and dark materials.

Other material units found on Ganymede were created by several types of impact features, ranging from impact craters to viscously relaxed impact features called palimpsests (Shoemaker and others, 1982) to the large impact basin, Gilgamesh, in the southern hemisphere.

Below, we summarize the properties of the imaging dataset used to construct the map, previously published maps of Ganymede, our own mapping rationale, and the geologic history of Ganymede. Additional details on these topics, along with detailed descriptions of the type localities for the material units, may be found in the companion paper to this map (Patterson and others, 2010).

\section{Image data}

This map is based on a global image mosaic of Voyager and Galileo data assembled by the U.S. Geological Survey (USGS) at a nominal resolution of $1 \mathrm{~km} /$ pixel (Becker and others, 2001). Voyager 1 partially imaged the subjovian hemisphere of Ganymede, while Voyager 2 partially imaged the antijovian hemisphere. Galileo imaging filled in most of the gaps in moderate-resolution coverage of the leading and trailing hemispheres.

Less than one-eighth of Ganymede's surface has been imaged at higher resolution than $1 \mathrm{~km} /$ pixel, but, where available, these higher resolution images were used to elucidate unit boundaries and aid geological interpretation. Most of the highresolution Voyager imagery that formed the core of the mosaic is available in the southern antijovian hemisphere and the northern subjovian hemisphere (fig. 1). Lighting and viewing angles are highly variable across the mosaic. Variations in emission angle (fig. 2) had the greatest effect on our ability to distinguish material units, with many subunits of light material becoming indistinguishable at high emission angles (near the limb). The uneven nature of imaging coverage at Ganymede has led to a global geologic map that is more detailed in some areas than others. In areas with high-resolution image coverage, the 1:15,000,000 scale of the map limited us to only delineating units larger than $30 \mathrm{~km}$ ( $2 \mathrm{~mm}$ at map scale). The ability to recognize characteristic morphological features used for defining map units drops off precipitously at image resolutions lower than $2 \mathrm{~km} /$ pixel and emission angles greater than $60^{\circ}$ (Patterson and others, 2010). Most of the undivided material units on the map occur in areas of low-resolution and (or) high-emission angle, most notably in the trailing hemisphere (near long $90^{\circ} \mathrm{E}$.).

\section{Relation to previous mapping}

After the Voyager encounters with Ganymede, several regional geologic maps were published at 1:5,000,000 scale, covering areas near the subjovian and antijovian points (Guest and others, 1988; Murchie and Head, 1989; Lucchitta and 
others, 1992; Croft and others, 1994; De Hon and others, 1994; Wagner and others, 1995; Wilhelms, 1997; Underwood and others, 1997). Galileo gap-fill imaging links the separate Voyager image sets together, permitting the production of a global map to link the understanding from the regional maps into a unified picture of Ganymede geology. The selection of units for this map was strongly influenced by the need to apply unit definitions consistently across images of widely variable resolution, incidence angle, and emission angle. Therefore, the range of consistently separable units is narrower than that found on some previously published regional maps. See Patterson and others (2010) for a unit-by-unit comparison to previous maps.

A common tension in planetary mapping is whether to explicitly map all structural features or whether to include them within the definitions of material units. The treatment of furrow structures in relation to dark material units in previous maps was inconsistent in this respect; some mappers treated furrows as structural features (for example, Guest and others, 1988), while others treated furrows as material units (for example, Lucchitta and others, 1992) or as both structural features and material units (for example, Underwood and others, 1997). This map separates furrows from the definition of dark material units and displays them as separate structural features. Previous regional maps of Ganymede consistently used grooves as part of the definition of light material units (for example, Murchie and Head, 1989; De Hon and others, 1994). Grooves are generally spaced a few km apart, so a map at the 1:15,000,000 scale that displayed all grooves as separate structural features would be indecipherable. Thus, grooves are included within the definition of material units on this map, and only representative groove orientations are displayed.

Several previous regional maps of Ganymede used rim degradation states to classify crater units (for example, Guest and others, 1988; Wagner and others, 1995). Because of highly variable lighting and viewing geometry of the source images used for this map, classification of craters based on the morphology of rim degradation could not be consistently and reliably applied across the globe. Thus, crater classification is based on more consistently observable criteria: the presence or absence of visible continuous ejecta and the albedo contrast of the crater or its rays with the surrounding material. The map only displays the continuous ejecta of craters; displaying discontinuous ejecta and crater rays obscures too much information about the underlying geology, so they were omitted from the map. Only craters larger than $30 \mathrm{~km}$ diameter are shown on the map; below this diameter the apparent density of mapped craters on the surface becomes a strong function of image resolution.

\section{Age determination}

Relative age relations of mapped units were determined based on crosscutting relations and differences in crater density. Dark cratered material (dc) is crosscut by grooves to form dark lineated material (dl). Dark materials and reticulate material are crosscut by light materials (fig. 3). Light materials are divided into three broad age categories based on crosscutting relations. The youngest light material units $\left(\lg _{3}, \mathrm{ls}_{3}, \mathrm{li}_{3}\right)$ are not crosscut by any other light units, while the oldest $\left(\lg _{1}, \mathrm{ls}_{1}, \mathrm{li}_{1}\right)$ are crosscut by all adjacent light units. Intermediate-age light material units $\left(\lg _{2}, \mathrm{Is}_{2}, \mathrm{li}_{2}\right)$ are crosscut by the youngest units, and intermediate units in turn crosscut the oldest units. Dark lineated $(\mathrm{dl})$ and reticulate $(r)$ materials sometimes share common groove spacing, morphology, and orientation with adjacent old light materials $\left(\lg _{1}, \mathrm{ls}_{1}, \mathrm{li}_{1}\right)$, indicating that they may have formed contemporaneously. Palimpsests are divided into ancient palimpsests $\left(\mathrm{p}_{1}\right)$, which are crosscut by light material, young palimpsests $\left(\mathrm{p}_{2}\right)$, which overlie light material, and undivided palimpsests (pu), which do not come in contact with light material and, thus, crosscutting relations cannot be used for relative age determination. The $\mathrm{p}_{2}$ palimpsests, Epigeous and Zakar, overlie all ages of light materials, Teshub overlies undivided light materials (I) and is cut by young light grooved material $\left(\lg _{3}\right)$, and Hathor overlies undivided light material $(I)$, while its secondary craters overlie old light subdued material $\left(\mathrm{Is}_{1}\right)$ and intermediate light grooved material $\left(\lg _{2}\right)$. All basin materials (br, bs, bi) overlie all ages of light materials. Some degraded crater materials $\left(c_{1}\right)$ are crosscut by dark lineated $(\mathrm{dl})$ and light materials, while other degraded crater materials overlie light materials. Partially degraded and fresh crater materials $\left(c_{2}, c_{3}\right)$ overlie all other material units.

Crater density statistics on the global map have large uncertainties due to inconsistent lighting and viewing geometries from one area to another. The shaded area of figure 4 shows crater density for the material units, using only the craters shown on this map ( $>30 \mathrm{~km}$ diameter) to compute density. Craters larger than $30 \mathrm{~km}$ diameter can be consistently mapped across the globe, but the number of craters is relatively small, providing poor statistics for map units with small areal coverage, and thus results are not shown for units br, bs, bi, $r, p_{1}, p_{2}$, $\mathrm{pu}$, and pi. The only firm conclusion that can be drawn from the $>30 \mathrm{~km}$ craters is that dark cratered material (dc) is old relative to $\lg _{3}, \mathrm{Is}_{3}, \mathrm{li}_{3}, \lg _{2}, \mathrm{Is}_{2}, \mathrm{li}_{2}, \lg _{1}, \mathrm{Is}_{1}, \mathrm{li}_{1}$, and dl. Better statistics using smaller diameter craters cannot be consistently performed on a global scale due to wide variations in available image data. Results from examining craters larger than $20 \mathrm{~km}$ diameter are shown in the white area of figure 4, giving better statistics for small units, with the caveat that craters may be undercounted in some areas with poor image coverage. This data also shows that dark cratered material has the highest crater density and, within error bars, the rest of the crater densities on material units are consistent with their crosscutting relations. See Patterson and others (2010) for further discussion of crater densities on mapped units.

\section{Geologic history}

The age relations on Ganymede, as illustrated in the Correlation of Map Units, show that Ganymede's geologic history can be divided into three distinct phases: before, during, and after the formation of light materials. The distinction between the first and second phases is typified by the 
high-resolution Galileo observation in figure 3 of intermediate light subdued material $\left(\mathrm{IS}_{2}\right)$ in Harpagia Sulcus crosscutting the dark cratered material (dc) of Nicholson Regio. The third phase begins with the formation of the Gilgamesh basin (br, bs, bi) on top of all light material units. Thus, we name the time before light material formation the Nicholsonian, we name the time during light material formation the Harpagian, and we name the time after light material formation the Gilgameshan.

\section{Nicholsonian Period}

Dark cratered material $(d c, d)$ is the oldest material unit on Ganymede. The formation of dark material through mixture of ice with refractory non-ice materials is a distinguishing process during the Nicholsonian. The surface of dark cratered material was bombarded by impactors, forming furrow structures, palimpsest materials $\left(\mathrm{p}_{1}, \mathrm{pu}, \mathrm{pi}\right)$, and degraded crater materials $\left(\mathrm{c}_{1}, \mathrm{Cu}\right)$.

\section{Harpagian Period}

During the Harpagian, almost two thirds of Ganymede was resurfaced by the formation of new material units. Tectonic deformation of dark cratered material formed dark lineated material $(\mathrm{dl}, \mathrm{d})$ and some reticulate material $(r)$. A combination of tectonism and (or) cryovolcanism produced a complex patchwork of light material units $\left(\mathrm{lg}_{3}, \mathrm{Is}_{3}, \mathrm{li}_{3}, \mathrm{Ig}_{2}, \mathrm{Is}_{2}, \mathrm{li}_{2}, \mathrm{lg}_{1}, \mathrm{Is}_{1}, \mathrm{li}_{1}\right.$, I) covering the majority of Ganymede's surface. Grooves and depressions formed as structural features during the Harpagian. Various areas of light subdued material have been interpreted to have a cryovolcanic origin (Schenk and others, 2001) or a crustal spreading origin similar to bands on Europa (Head and others, 2002). The two light units that cover the greatest surface area are old subdued light material $\left(\mathbf{I}_{1}\right)$ and young grooved light material $\left(\mathrm{lg}_{3}\right)$, indicating a possible shift from cryovolcanic to tectonic processes through the Harpagian. Also during this period, large impacts continued to produce palimpsest materials $\left(\mathrm{p}_{2}, \mathrm{pu}, \mathrm{pi}\right)$, and more degraded crater materials $\left(c_{1}, \mathrm{cu}\right)$ formed.

\section{Gilgameshan Period}

Only impact-related materials have formed during the Gilgameshan. A very large impact formed basin materials (br, bs, bi) at Gilgamesh. A small amount of palimpsest materials $\left(p_{2}, p u, p i\right)$ formed early in this period, but later large impacts formed features that exhibit more topographic relief and more typical crater morphology. An interpretation of this change in crater morphology is that heat flow decreased dramatically during this time period, thickening the cold elastic layer of ice near the surface. The last of the degraded crater materials $\left(c_{1}, c u\right)$ formed early in this period, while later impacts formed partially degraded crater materials $\left(\mathrm{C}_{2}, \mathrm{Cu}\right)$, followed by fresh crater materials $\left(\mathrm{C}_{3}, \mathrm{Cu}\right)$ in the most recent times.

Crater rims and domes appear to have formed throughout the history of Ganymede. The secondary craters shown on the map are associated with craters formed in the Gilgameshan Period.

\section{References Cited}

Becker, T., Archinal, B., Colvin, T., and 4 others, 2001, Final digital global maps of Ganymede, Europa, and Callisto, in Lunar and Planetary Science Conference, XXXII: Houston, Tex., Lunar and Planetary Institute, abstract no. 2009.

Croft, S., Cassachia, R., and Strom, R., 1994, Geologic map of the Tiamat Sulcus (Jg-9) quadrangle of Ganymede: U.S. Geological Survey Miscellaneous Investigations Map I-2328, scale 1:5,000,000.

De Hon, R.A., Leith, A.C., and McKinnon, W.B., 1994, Geologic map of the Hathor region (Jg-15) of Ganymede: U.S. Geological Survey Miscellaneous Investigations Map I-2388, scale 1:5,000,000.

Guest, J.E., Bianchi, R., and Greeley, R., 1988, Geologic map of the Uruk Sulcus (Jg-8) quadrangle of Ganymede: U.S. Geological Survey Miscellaneous Investigations Map I-1934, scale 1:5,000,000.

Head, J.W., Pappalardo, R.T., Collins, G.C., and 8 others, 2002, Evidence for Europa-like tectonic resurfacing styles on Ganymede: Geophysical Research Letters, v. 29, p. 2151.

Lucchitta, B.K., Barnes, C.W., and Glotfelty, M.F., 1992, Geologic map of the Memphis Facula (Jg-7) quadrangle of Ganymede: U.S. Geological Survey Miscellaneous Investigations Map I-2289, scale 1:5,000,000.

Moore, J.M., Asphaug, E., Morrison, D., and 11 others, 1999, Mass movement and landform degradation on the icy Galilean satellites: Icarus, v. 140, p. 294-312.

Murchie, S.L., and Head, J.W., 1989, Geologic map of the Philus Sulcus (Jg-4) quadrangle of Ganymede: U.S. Geological Survey Miscellaneous Investigations Map I-1966, scale 1:5,000,000.

Pappalardo, R.T., and Collins, G.C., 2005, Strained craters on Ganymede: Journal of Structural Geology, v. 27, p. 827-838.

Pappalardo, R.T., Collins, G.C., Head, J.W., and 6 others, 2004, Geology of Ganymede, in Bagenal, F., Dowling, T., McKinnon, W., eds., Jupiter: Cambridge, UK, Cambridge University Press, p. 363-396.

Pappalardo, R.T., Head, J.W., Collins, G.C., and 13 others, 1998, Grooved terrain on Ganymede: Icarus, v. 135, p. 276-302.

Patterson, G.W., Collins, G.C., Head, J.W., and 4 others, 2010, Global geological mapping of Ganymede: Icarus, v. 207, p. 845-867.

Prockter, L.M., Head, J.W., Pappalardo, R.T., and 12 others, 1998, Dark terrain on Ganymede: Icarus, v. 135, p. 317-344.

Schenk, P.M., McKinnon, W.B., Gwynn, D., and Moore, J.M., 2001, Flooding of Ganymede's bright terrains by lowviscosity water-ice lavas: Nature, v. 410, p. 57-60.

Shoemaker, E.M., Lucchitta, B.K., Wilhelms, D.E., Plescia, J.B., and Squyres, S.W., 1982, The geology of Ganymede, in Morrison, D., ed., Satellites of Jupiter: Tucson, University of Arizona Press, p. 435-520.

Underwood, J.R., Casacchia, R., Woronow, A., and Teeling, M.J., 1997, Geologic map of the Galileo Regio 
quadrangle ( $\mathrm{Jg}-3)$ of Ganymede: U.S. Geological

Survey Miscellaneous Investigations Map I-2534, scale 1:5,000,000.

Wagner, R.J., Jaumann, R., and Neukum, G.P., 1995, Geologic map of the Etana region (Jg-1) of Ganymede: U.S.

Geological Survey Miscellaneous Investigations Map I-2497, scale 1:5,000,000.

Wilhelms, D.E., 1997, Geologic map of the Osiris (Jg-12) and Apsu (Jg-13) quadrangles of Ganymede: U.S. Geological Survey Miscellaneous Investigations Map I-2422, scale 1:5,000,000. 